\title{
Urban Sprawl Monitoring
}

\author{
Sassan Mohammady ${ }^{1} \&$ Mahmoud Reza Delavar ${ }^{2}$ \\ ${ }^{1}$ GIS division, Dept. Of Surveying and Geomatics Eng., College of Enginnering, University of Tehran, Tehran, \\ Iran \\ ${ }^{2}$ Center of Excellence in Geomatics Eng. in Disaster Management, Dept. of Surveying and Geomatics Eng., \\ College of Eng., University of Tehran, Tehran, Iran \\ Correspondence: Sassan Mohamamdy GIS division, Dept. Of Surveying and Geomatics Eng., College of \\ Enginnering, University of Tehran, North Karegar St, Tehran, Iran. Tel: 98-936-371-2267. E-mail: \\ Sassanmohammady@ut.ac.ir
}

Received: December 18, $2014 \quad$ Accepted: January 11, 2015 Online Published: February 28, 2015

doi:10.5539/mas.v9n8p1

URL: http://dx.doi.org/10.5539/mas.v9n8p1

\begin{abstract}
Urban sprawl is a common phenomenon in developed and developing countries. Population growth and immigration to cities are the most important reason to such urban expansions. Out layer growths which in the most cases results sprawl has so many attractions such as low rate of crime, lower costs of living and clean air. These are probably the reasons to rapid increase of this phenomenon. Urban sprawl is a kind of growth in cities which have derived so many negative impacts such as agriculture and natural land loss, environmental pollution, high rate of travel time and costs, high rate of energy consuming and etc.,. Thus, analyzing and monitoring urban area is a key task for urban planning to inform about urban growth. Numerous researches have attempted to characterize and explain urban sprawl. In this study, we implemented Shannon Entropy for assessments of urban sprawl. The case study is Tehran Metropolis which has experienced so fast urbanization and population growth in the recent decades.
\end{abstract}

Keywords: urban, sprawl assessment, Tehran metropolis

\section{Introduction}

\subsection{Introduce the Problem}

Nowadays, a large number of cities in the developing and developed countries are witnessing urban sprawl as a common phenomenon which causes so many issues. This phenomenon in particular is different from expansion (Galster et al., 2001, Inostroza et al., 2013). In fact, urban sprawl is defined as a specific form of urban dispersed development with low-density, auto-dependent with environmentally and socially impacts (Hasse and Lathrop 2003).

The most important negative impacts of sprawl is that this kind of development causes the increase of car-dependency for transportation (Torrens and Alberti, 2000), the loss of agricultural, green spaces and natural land, increase in energy consumption, the need for more infrastructure (Bruekner, 2001) and increase in infrastructure costs, longer travel times, increasing automobile trips and costs of travel and, therefore, greater environmental pollution, the degradation of periurban ecosystems (Johnson, 2001, Li et al., 2006). Generally, sprawl is defined as a relatively wasteful method of urbanization, characterized by uniform low densities and this phenomenon is often uncoordinated and extends along the fringes of metropolitan areas. It invades upon prime agricultural and resource land in the process (Alberti and Torrens, 2000). This form of urban growth is a common phenomenon in the developed countries and also in the developing countries which has big undesirable environmental and socioeconomic effects such as soil recourses and weather pollution (Zhang 2007, Pourahmad et al 2007), prolific farming lands loss around the cities (Brabec and Smith, 2002, Zhang 2000), and land use fragmentation and loss of biodiversity (Alberti 2005), high ecological footprint (Muniz and Galindo 2005), the decrease of even access to urban services and amenities (Burton 2001), increased traffic and demand for mobility (Ewing et al 2002), destruction of forest cover (Rudel and McDonald 2005), high automobile dependency and as a result exacerbate global warming (Hamin and Guran 2009).

Rapid urbanization is quite alarming, especially in developing countries (Kumar et al 2007). This rapid urbanization in so many cases lead to urban sprawl. Urban sprawl has been identified as an undesired trend in 
many countries (Hayek et al 2011). Iran as a developing country has experienced urban sprawl in many of large, medium-size or even small cities (Roshan et al 2009). Cities in the developing countries lack such type of policies in most of the cases and they grow with all freedoms (Bhatta 2009). In developing countries due to the lack of timely information of the urbanization process and its long-term ecological impacts, urban planners have not been able to analyze consistently and restore the ecosystems in peri-urban areas (Dutta 2012). In Iran, population growth and urban sprawl have always played an important role in environmental degradation with a strong pressure on local, regional and global conditions (Akbari Motlaq and Abbaszadeh 2012).

Sprawl pattern and land use changes could be detected and analyzed cost effectively and efficiently using remote sensing data and geospatial information systems (GIS) techniques (Bhatta 2009, Barnes et al 2001). Monitoring of urban growth and understanding landscape characterization through historical and timely information provides the necessary information to evaluate environmental impacts of land use change, to determine future infrastructure requirements and to delineate urban growth and municipal service areas (Kennedy 2007).

Remote sensing is considered to be an appropriate source of urban data to support urban studies (Donnay et al., 2001). Urban expansion can be quantified by measuring the built-up area change between two dates (Jensen, 2005). Remote sensing as a reliable source of data is critical for areas with rapid land use changes and especially where the updating of information is tedious and time-consuming. In urban studies, monitoring of urban development is mainly to find out the type, amount, and location of land conversion (Yeh and Li, 1999).

In this study we implemented Shannon Entropy method for analyzing and measuring urban sprawl between 1988 and 2010. In the second step, we introduced an indicator for evaluating sprawl for Tehran Metropolis.

\section{Method}

Spatial metrics as a valuable tool have been used for the analyzing, monitoring, and tracking of changes in land use patterns and shapes in many research studies (Aguilera et al 2011, Kim and Ellis 2009). In this study after introducing the study area, we implemented Shannon Entropy for analyzing urban sprawl for Tehran Metropolis. The Shannon's entropy reflects the dispersion of the spatial variable in a specified area (Yeh and Li 2001). The Shannon's Entropy can be calculated from the remotely sensed data to efficiently identify and characterize the urban sprawl (Torrens and Alberti 2000, Yeh and Li 2001, Lata et al 2001, Sudhira et al 2004).

\subsection{Study Area}

The case study in this research is the city of Tehran, Iran. Tehran as the capital of Iran has experienced rapid expansion due to the rapid growth of population and besides this city has become the main target of immigration due to its great urbanization attractions (Roshan et al 2009). Figure 1 shows the position of this city in Iran. Tehran has experienced rapid urban population growth in the last few decades. Figure 2 shows rapid population growth in Tehran Metropolis in the last few decades.

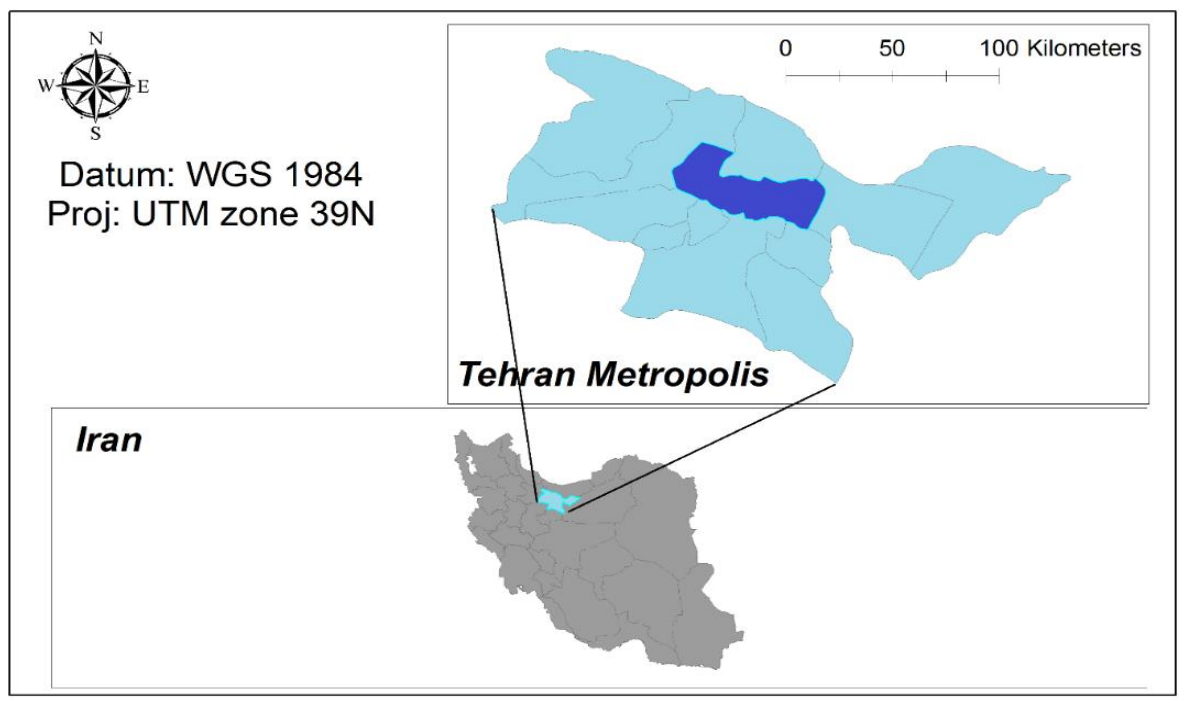

Figure 1. The study area 


\section{Tehran urban population growth}

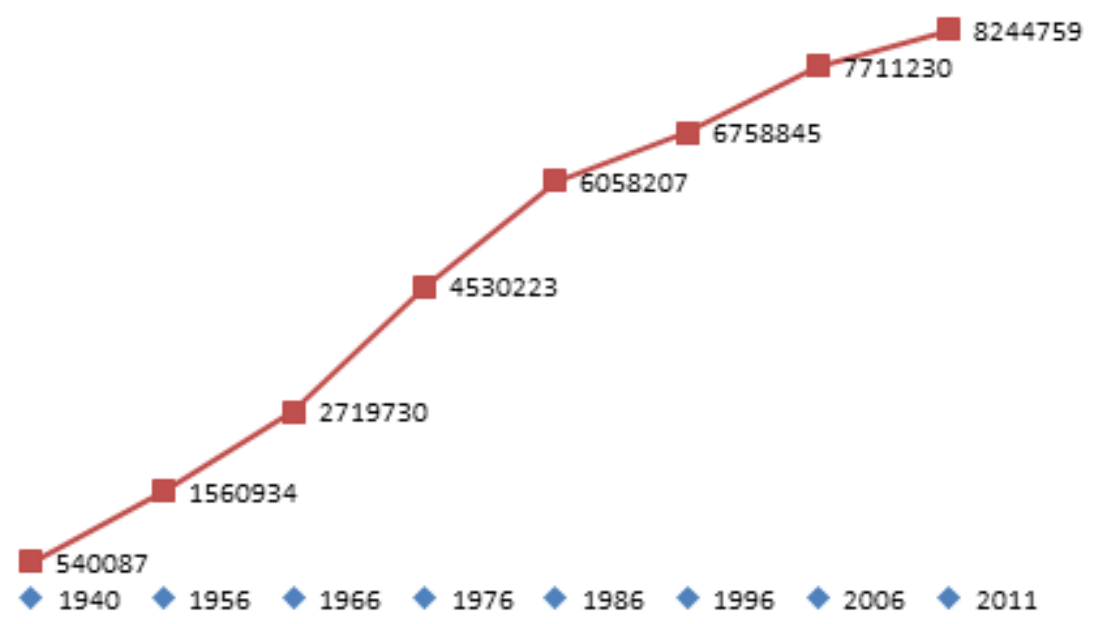

Figure 2. Urban population growth in Tehran

\subsection{Pre Processing}

Landsat imageries acquired at 1988, 1999 and 2010 with ground pixel size 28.5 Meter have been used (Table. 1). All of remote sensing processes have done in ENVI 4.8. The related imageries are classified based on Anderson Level 1 (Anderson et al 1976) with Support Vector Machine (SVM) classification. Support vector machines (SVM) due to its ability to handle the nonlinear classifier problems are applied in so many researches (Aghababaee et al 2012). Classification accuracies are presented in Table 2.

Table 1. Satellite imageries

\begin{tabular}{llllll}
\hline Date & Sensor & Ground Pixel Size $(\mathrm{m})$ & Satellite & Datum & Projection System \\
\hline Sep.27, 1988 & TM & 28.5 & Landsat-5 & WGS-1984 & UTM, Zone 39N \\
Oct.7, 1999 & ETM $^{+}$ & 28.5 & Landsat-7 & WGS-1984 & UTM, Zone 39N \\
Oct. 17, 2010 & ETM $^{+}$ & 28.5 & Landsat-7 & WGS-1984 & UTM, Zone 39N \\
\hline
\end{tabular}

Table 2. Classification assessments

\begin{tabular}{lll}
\hline Data & Overall Accuracy (\%) & Kappa Statistics $(\%)$ \\
\hline 1988 & 89.43 & 82.22 \\
1999 & 87.12 & 72.73 \\
2010 & 91.33 & 88.67 \\
\hline
\end{tabular}

According to (Thomlinson et al 1999) all of the overall accuracies are acceptable. According to (Pijanowski et al 2005), 1988 and 2010 classification resulted are considered as excellent and 1999 classification result is considered as very good.

With increased accessibility and improved quality of spatio-temporal remote sensing data as well as new analytical techniques, it enables us to monitor and analyze urban growth and land use change in a cost-effective and timely manner (Alberti 2005, Herold et al 2003). Table 3 shows urban and non-urban area in Tehran Metropolis in 1988, 1999 and 2010. Figure 3 presents Tehran urban area in 1988, 1999 and 2010. 


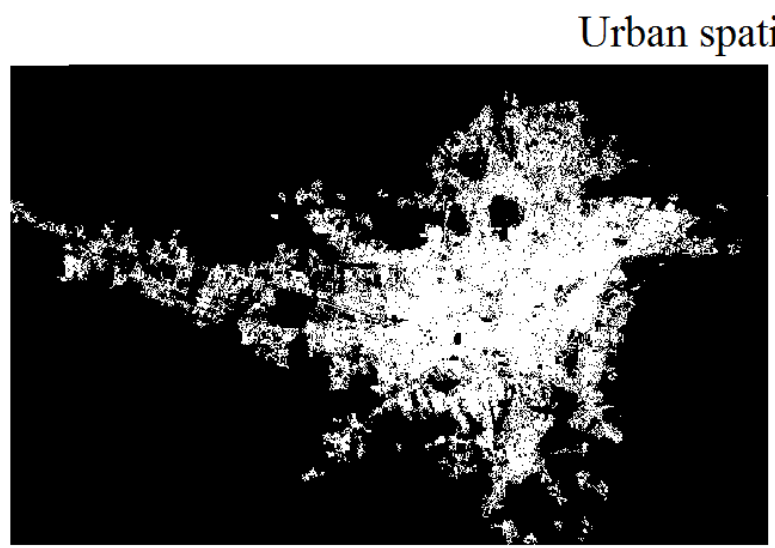

1988

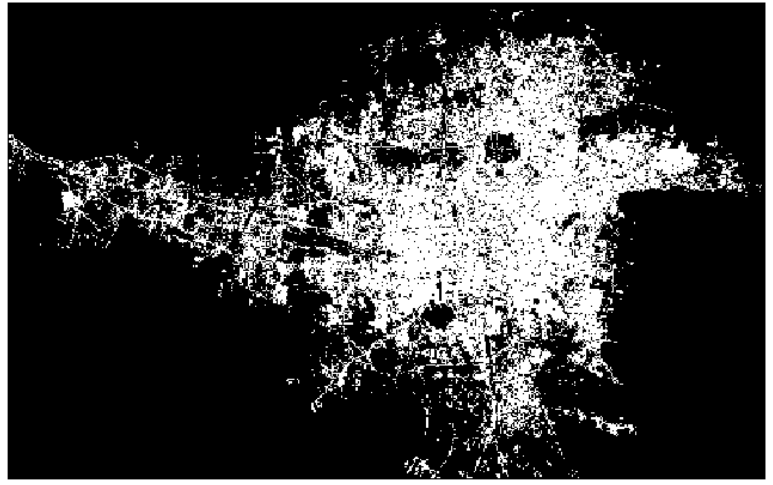

1999
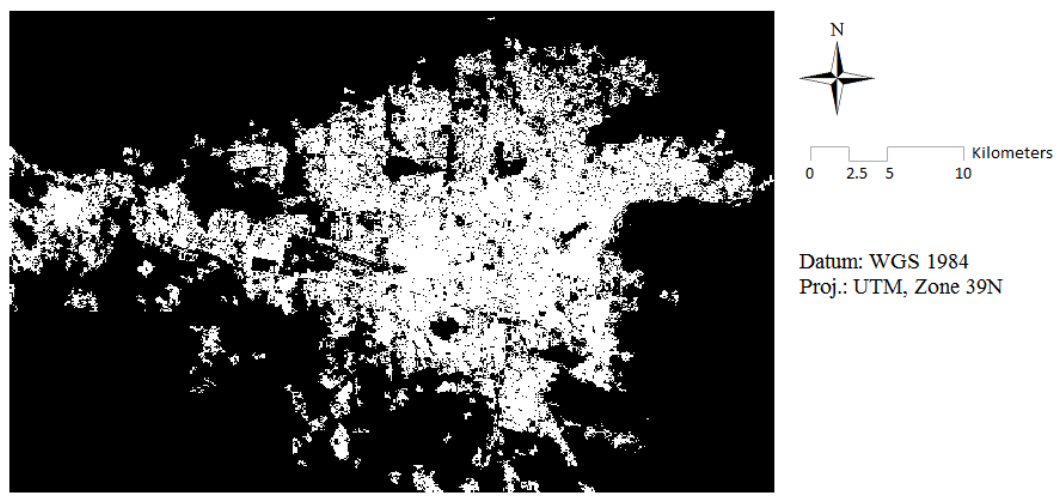

2010

Figure 3. Tehran urban area in 1988, 1999 and 2010

Table 3. Urban and non-urban area in 1988, 1999 and 2010

\begin{tabular}{lllll}
\hline Data & Urban Area $\left(\mathrm{Km}^{2}\right)$ & Urban Area $(\%)$ & Non-Urban Area $\left(\mathrm{Km}^{2}\right)$ & Non-Urban Area $(\%)$ \\
\hline 1988 & 298.813 & 18.02 & 1359.477 & 81.98 \\
1999 & 345.9779 & 20.86 & 1312.312 & 79.14 \\
2010 & 428.0549 & 25.81 & 1230.235 & 74.19 \\
\hline
\end{tabular}

\section{Results}

In this study, we implemented Shannon Entropy for analyzing urban sprawl in Tehran Metropolis during 1988 to 2010. Shannon's entropy is a well-accepted method for determining the sprawled urban pattern (Li and Yeh, 2004; Sudhira et al., 2004; Yeh and Li, 2001). Shannon Entropy can be used to analysis urban sprawl in temporal span or zone wise. It means it can be used to clarify sprawl for a period of time (temporal span) and for each zone separately (zone wise). In this study we defined the zones according to distance to center. In other words, the distance between each urban pixel and center is calculated and categorized using 2500 meter interval. Each different zone has a different level of compactness leading to different patterns of growth. Therefore, a single policy for the entire city never works with equal degrees of effectiveness for all (Bhatta 2009). The implemented Shannon Entropy is defined below:

$$
H_{i}=-\sum_{j=1}^{m} p_{j} \log _{e}\left(p_{j}\right)
$$

where,

$H_{i}=$ Shannon Entropy for each temporal span, 
$p_{j}=$ proportion of built up area in $\mathrm{j}$ zone to total built up area.

$\mathrm{j}$ is the number of zones $(\mathrm{m}=13)$.

$\mathrm{i}$ is temporal span $(1,2)$.

This value ranges from 0 to $\log _{e}(m)$, values closer to 0 indicate very compact distribution and the value closer to $\log _{e}(m)$ indicates that the distribution is much dispersed. In other words, larger value of entropy indicates the occurrence of urban sprawl. Table 4 presents Shannon Entropy for each temporal span. According to Bhatta et al (2009), half of the $\log _{e}(m)$ is a threshold for determining urban sprawl. In this study due to $\mathrm{m}=13$, this value is 1.2825. It means if Shannon Entropy in any of them is larger than this value, it can safety said this region is sprawled and if become less than this value, the region is non-sprawling. According to Table 4, in both temporal spans (1988 to 1999 and 1999 to 2010) this city has experienced sprawl and Shannon Entropy for this city become bigger. It means, this city becoming more sprawling. Figure 4 shows urban cells in each zone. The urban expansion between 1988 and 2010 covered greater areas especially in west and north directions and this expansion occurred at distance from the center (Figure 4).

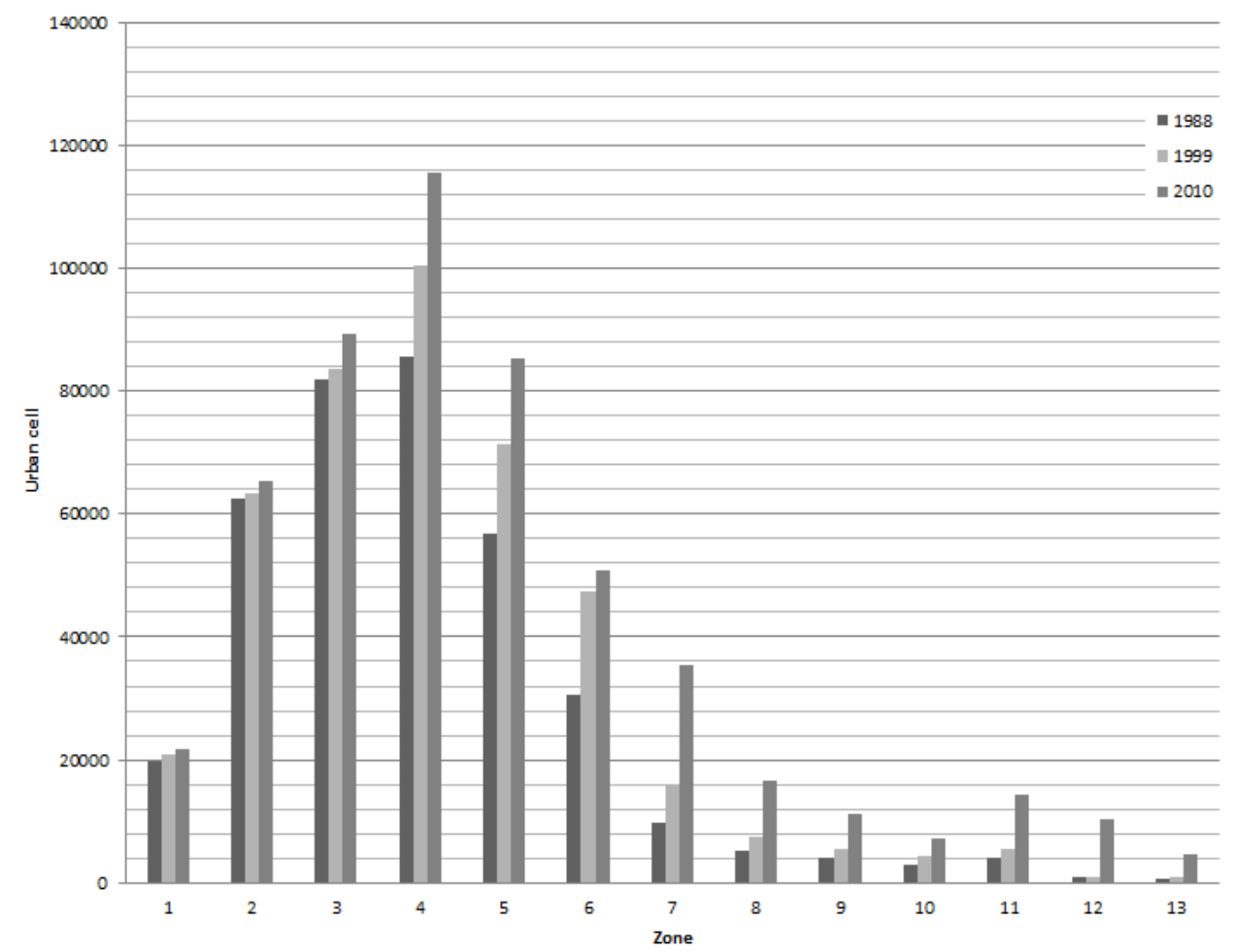

Figure 4. Urban cells in each zone

Table 4. Shannon Entropy during 1988 to 1999 and 1999 to 2010

\begin{tabular}{lll}
\hline Temporal Span & $1988-1999$ & $1999-2010$ \\
\hline Shannon Entropy & 1.9002 & 2.3088 \\
\hline
\end{tabular}

Distance to center is a key factor in urban expansion. As this factor growth, urban sprawl and dispersed expansion will happen. When distance urban cell in a city from center increase, travel time, trip costs, pollution, and agricultural land lost and so many negative impacts will increase, too. This factor clarifies the importance of vertical expansion in the cities. Figure 5 shows the dispersion of the urban cells in 1988, 1999 and 2010. The number of urban cells in larger distance to center in Tehran Metropolis during the time has increased. According to Figure 5, number of the urban cell in during 1988 to 1999 with distances larger than $9 \mathrm{Km}$ has increased and this expansion in more distant area has been so fast in 1999 to 2010. 


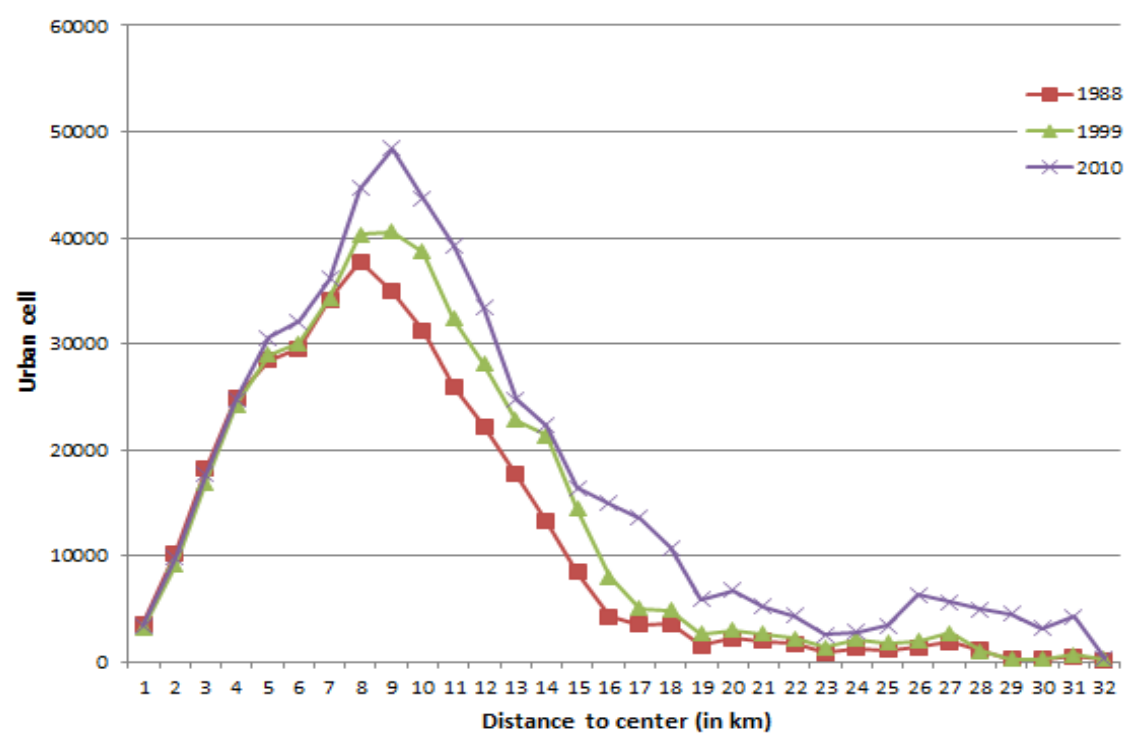

Figure 5. Dispersion of the urban cells in 1988, 1999 and 2010

\subsection{Sprawl Index}

Geospatial Information Systems (GIS) are widely used to represent, analyze, and display various spatial data such as topographic maps, satellite imageries and Digital Elevation Model (DEM). Many researchers use GIS as a reliable science and technology to find the spatiotemporal characteristics of landscape (Xie and Cho 2007). Using remote sensing data with GIS techniques provides a powerful tool to analyze, model and project environmental change. Therefore, integration of remote sensing and GIS have been recognized as powerful and effective methods in monitoring environmental change, especially in detecting the land use/land cover change (LUCC) (Herold et al 2003, Gao et al 2006). In the second step in this paper, the Sprawl Index (SI) is calculated, by means of specific GIS modeling, using thematic degrees of propensity to the phenomenon that depend on a set of territorial (morphological-urban development) characteristics: slope, elevation, aspect, distance to main road, distance to center, agriculture consistency, green spaces consistency, planning consistency and distance to commercial center (Table 5). The Sprawl Index (SI) is calculated through the following equation that contains a set of degrees of settlement location sensitivity to the aforementioned territorial and morphological characteristics. Figure 6 shows the sprawl parameters.

Table 5. Important parameters for obtaining SI map

\begin{tabular}{ll}
\hline Parameters & Refers \\
\hline Distance to Centers (DC) & Ewing et al, 2002 \\
Slope & Romano 2004 \\
Elevation & Romano 2004 \\
Aspect & Romano 2004 \\
Distance to Main Roads (DM) & Ewing et al, 2002, Romano 2004 \\
Planning Consistency (PC) & Jiang et al, 2007 \\
Open Spaces Consistency (OSC) & Jiang et al, 2007, Sim \& Mesev, 2011 \\
Agriculture Consistency (AC) & Jiang et al, 2007 \\
Distance to Commercial Centers (DCC) & Ewing et al, 2002, Romano 2004 \\
\hline
\end{tabular}

Sprawl Index is obtained from implementation of 9 parameters. Sprawl Index is defined,

Sprawl Index (SI) =DC+ Slope+ Elevation+ Aspect+ DM+ PC+ OSC+ AC+ DCC. 
Figures 6 and 7 show all of 9 parameters and the resulted SI map, respectively.
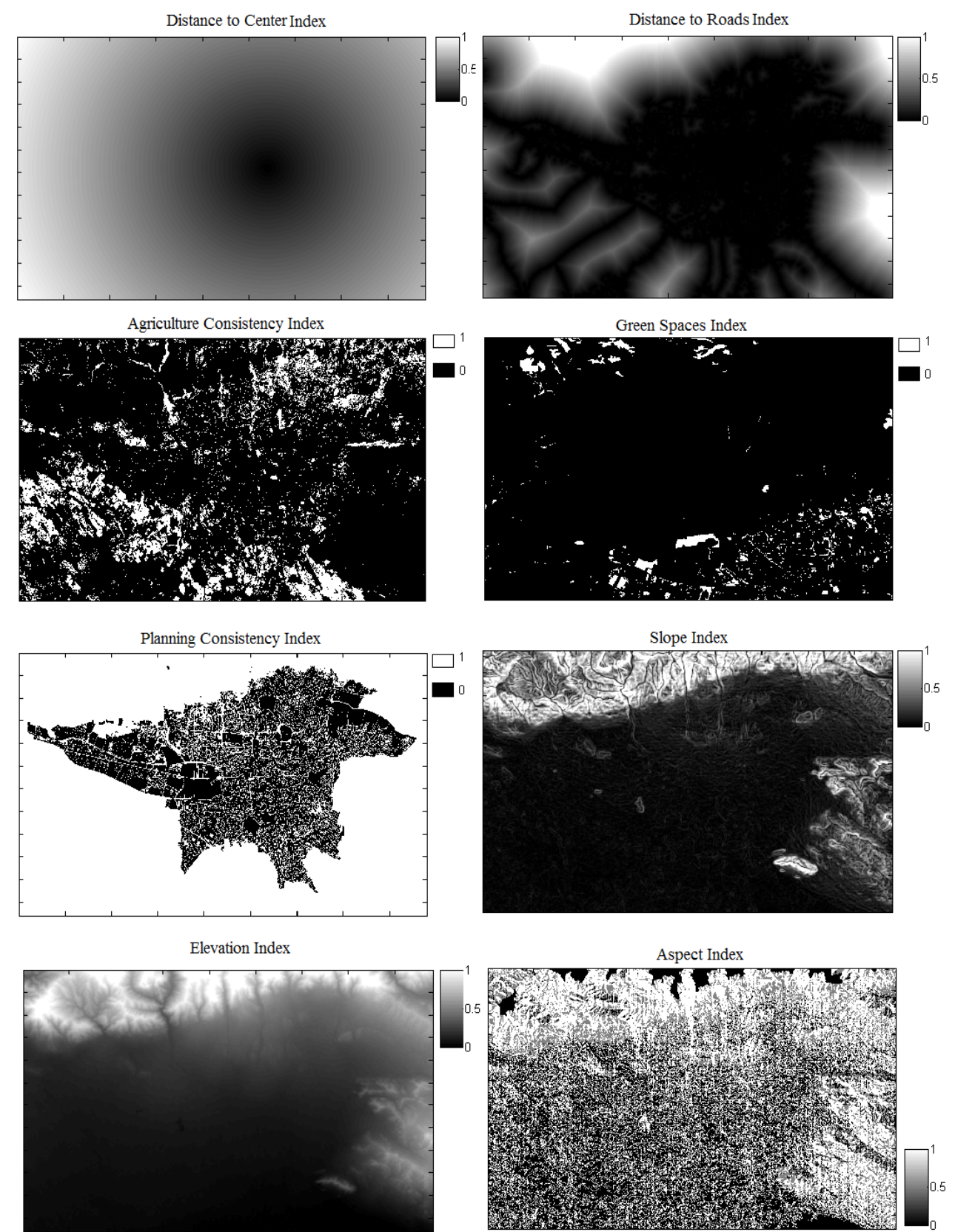

Distance to Commercial Centers Index
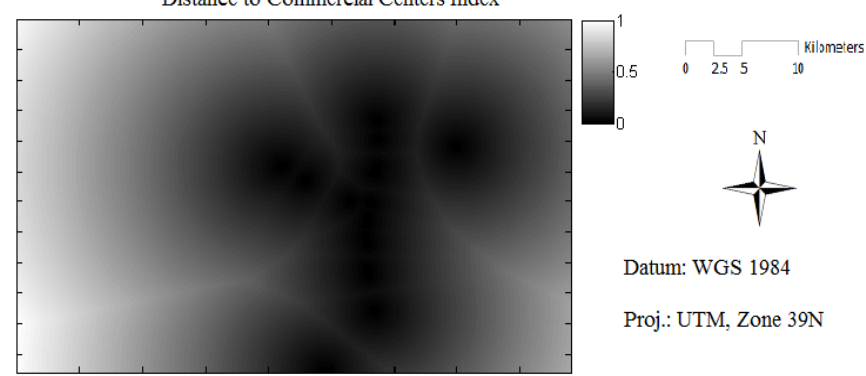

Datum: WGS 1984

Proj.: UTM, Zone 39N

Figure 6. Important parameters for determining SI 


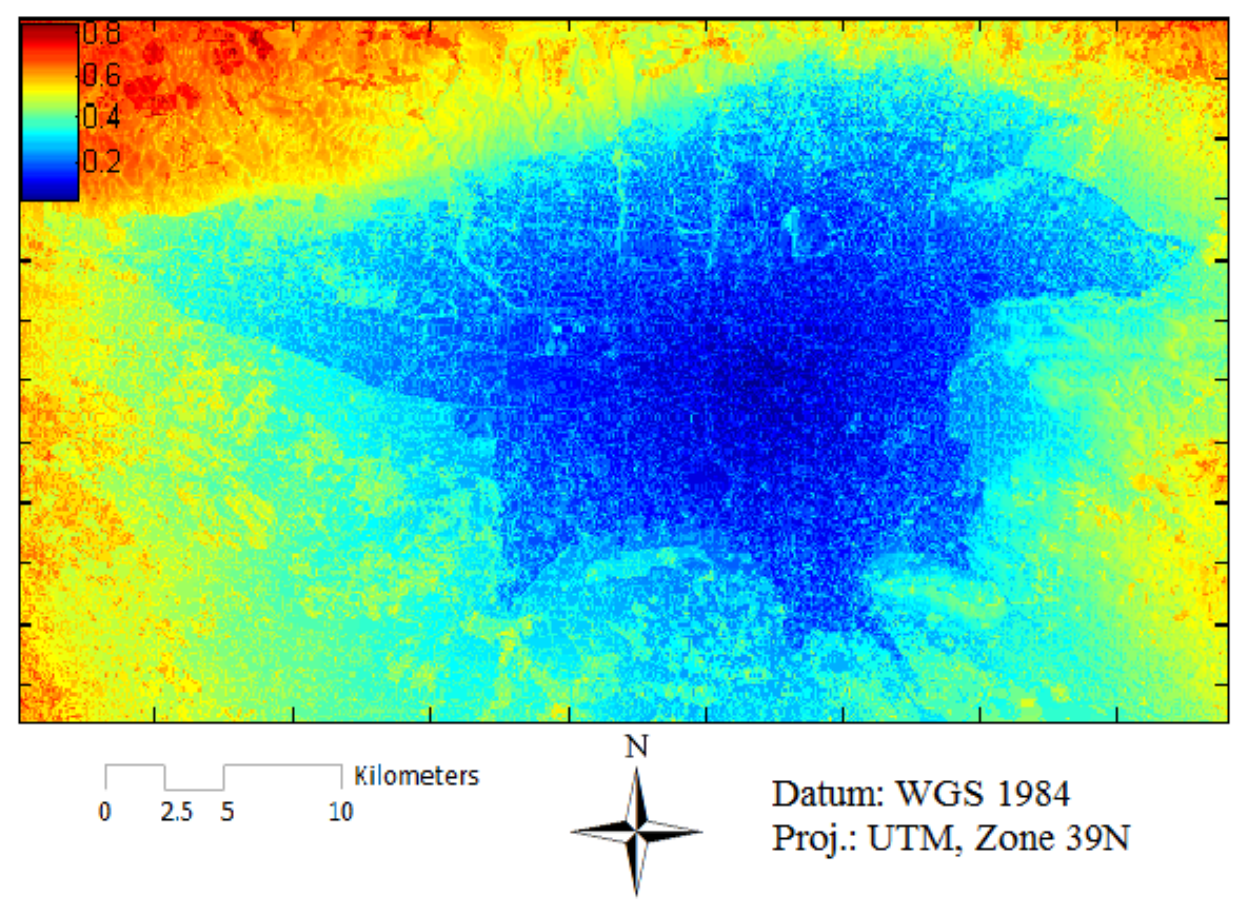

Figure 7. The SI resulted map

According to Figure 7, many part of Tehran Metropolis areas are developed in regions with approximately moderate or high level degrees of sprawl. This means these region is considered as a sprawl region. In Figure 8, we categorize SI range value between 0 to 1 in 5 classes.

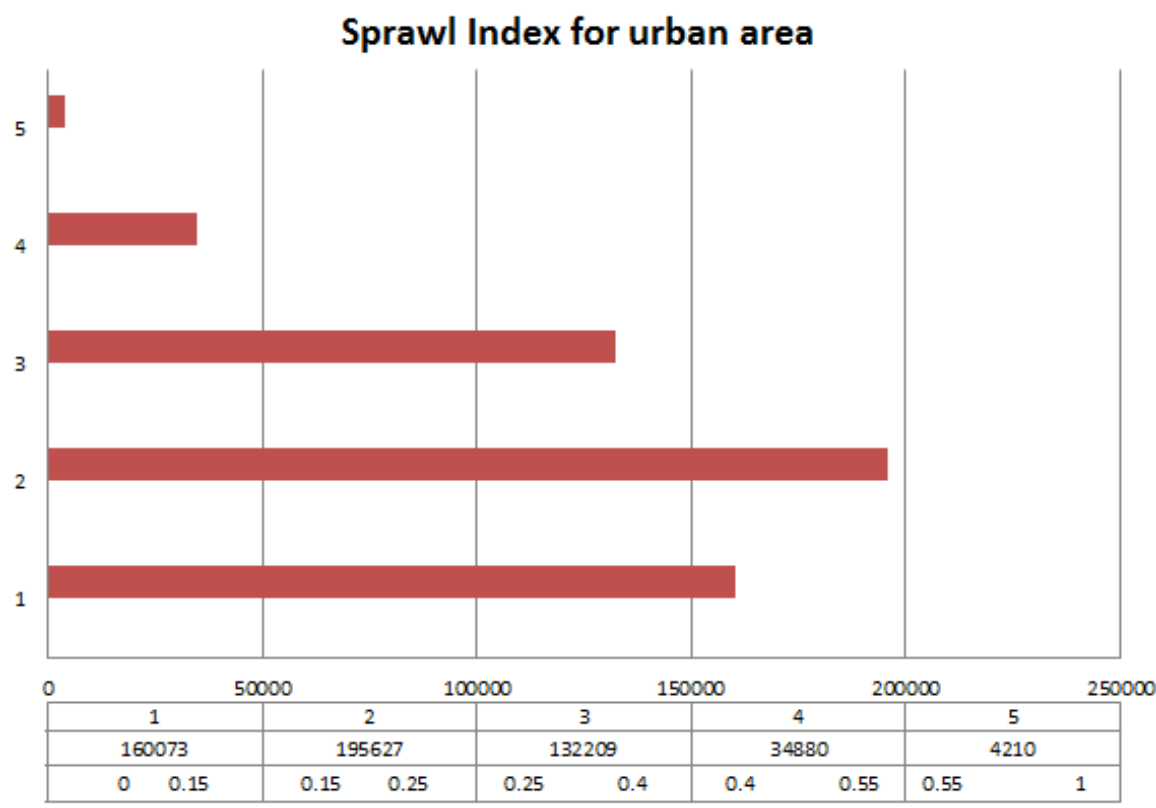

Figure 8. Categorized SI map

As the results are shown in Figure 8, the number of urban cell with SI bigger than 0.4 are 39090 cells. It means huge areas in the city are developed in area with high degree of sprawl. At the other side, some part of area in the class number 3 has approximately the big value of SI and these regions have the same problems.

In this research we have used three Landsat imageries with ground pixel size $28.5 \mathrm{~m}$ resolutions. Number and date of these satellite imageries is an important issue in studies like urban sprawl. Because as number of satellite 
imageries increase and the interval period of the imageries become even, the research precision and reliability will increase. In this research due to lack of comprehensive data (from number view) we have used three imageries. Also, resolution of the imageries is another important issue. Because as ground resolution of the imageries decrease, obviously, classification error in ground scale will decrease and this make the calculations accuracy increase.

\section{Discussion \& Conclusion}

Since the 1988, the most important urban expansion has taken place in the North and Northwestern region of the city. These regions probably due to their appropriate elevation and slope situation and fast transportation networks growth have experienced such great expansions.

According to Table 4, Shannon Entropy for temporal span 1988-1999 is calculated 0.9667. The half of $\log _{e}(m)$ is 0.6931. Thus, according to earlier works (Bhatta et al 2010), it can be say due to bigger than the half of $\log _{e}(m)$, in this period; this city is considered as sprawled. For the second temporal span 1999-2010, Shannon entropy is calculated 1.0422 and this criterion has increased from 0.9667 in 1988-1999 to 1.0422 in 1999-2010. It seems the tendency to sprawl in this city has increased. This result obviously confirms that this city is becoming more sprawling.

As the result is shown in Figure 7, many area of this city have the SI indexes more than 0.4. Construction over the planning schemes, construction without considering urban planning criterion and so many reasons are causes to this sprawl condition in this city. A part of this inconsistency and uneven growth is derived from lack of temporal, sufficient and reliable data about history of the city.

This research can be considered as a useful method for analyzing urban growth in any cities. It should be mentioned that there are so many sprawl assessments factor for monitoring urban sprawl, but due to lack of sufficient and comprehensive data for analyzing urban and it landscape's and at the other side, practical methods which have been used in this research, it can be assumed as a powerful and great step for analyzing and monitoring urban growth in many cities. Integration of GIS, remote sensing data and statistical methods has been so productive in so many fields especially in urban planning.

According to the finding in Table 4, Tehran is sprawled and this city is becoming more sprawled. Urban growth in this city due to population growth, attraction of the city as the capital of Iran and social, economic potential of the city have increased so fast. These factors have resulted urban land and urban population growth so fast in this city.

Cities unavoidably will expand, but how to control the urban development while avoiding sprawl is an issue of urban planning. One of the solutions for this uneven dispersion is implementation of some policies that aim to restrict urban expansion in the cities to make them more compact. In other words, the policies should cover vertical growth and infilling growths of the city instead of edge expansion and out-filling expansion.

According to Figure 8, approximately all of expansion has occurred in area with distance larger than $4 \mathrm{~km}$. A great part of these expansions have occurred in the area with distances larger than $9 \mathrm{~km}$ especially during 1999 to 2010. Trend to settlements in the distant area from center has increased especially during 1999 to 2010. Lower cost of living, cleaner air and so many reasons such as personal preferences, safety neighborhood and low range of crimes are probably the reasons for this huge expansion instead of vertical growth of the main parts of the city. But as we know it causes a lot of problems such as increasing numbers of travels and travel costs, agriculture and natural and open space loss, insufficient infrastructure and high infrastructure costs.

This research can be considered as an alarming to urban planners to inform them about situations of this city. Combination of GIS and remote sensing data can be used as a powerful method for analyzing urban growths. This should encourage urban managers and policy makers to implement such methods for determining development scenario.

Three satellite imageries have been used to analysis urban sprawl for Tehran Metropolis. The greater number of satellite imageries and using imageries with smaller ground pixel size definitely increase accuracy and reliability of results. But it should be mentioned for a developing country like Iran which historical urban data and land use map is not stored properly or even existed, this research using free and reliable satellite imageries data which approximately is the single source of data for these regions is a practical and scientific method for analyzing urban growth.

One of the major issues in cities intelligent management is the lack of proper and scientific development and as a result urban development in high slope and elevations, destruction of agricultural land, increased infrastructure and utilities costs, environmental deteriorate and natural hazards and the lack of optimum use of land have been 
encountered (Mohammady et al, 2013).

An important finding of this study is the fact that this city in both the periods (1988-1999 and 1999-2010) has experienced sprawl and unfortunately, this trend is becoming larger.

\section{References}

Aghababaee, H., Amini, J., \& Tzeng, Y. C. (2013). Contextual PolSAR image classification using fractal dimension and support vector machines. European Journal of Remote Sensing, 46, 317-332. http://dx.doi.org/10.5721/EuJRS20134618

Aguilera, F., Valenzuela, L., \& Botequilha-Leitão, A. (2011). Landscape metrics in the analysis of urban land use patterns: A case study in a Spanish metropolitan area, Landscape and Urban Planning, 99, 226-238.

Akbari, M. M., \& Abbaszadeh, G. (2013). The Physical Development of Mashhad City and Its Environmental Impacts. Environment and Urbanization Asia, 3(1), 79-91.

Alberti, M. (2005). The effects of urban patterns on ecosystem function. International Regional Science Review, 28(2), 168-192.

Anderson, J. R, Hardy, E. E., Roach, J. T., \& Witmer, R. E. (1976). A land use and land cover classification system for use with remote sensor data. US Geological Survey, Professional Paper, 964(28), Reston, VA/

Barnes, K. B., Morgan, J. M., Roberge, M. C., \& Lowe, S. (2001). Sprawl development: Its patterns, consequences, and measurement, A white paper, Towson University. Retrieved from http://chesapeake. towson.edu/landscape/urbansprawl/download/Sprawl_white_paper.pdf

Bhatta, B. (2009). Analysis of urban growth pattern using remote sensing and GIS: a case study of Kolkata, India. International Journal of Remote Sensing, 30(18), 4733-4746.

Bhatta, B., Saraswati, S., \& Bandyopadhyay, D. (2010). Quantifying the degree-of-freedom, degree-of-sprawl, and degree-of-goodness of urban growth from remote sensing data. Applied Geography, 30, 96-111.

Brabec, E., \& Smith, C. (2002). Agricultural land fragmentation: the spatial effects of three land protection strategies in the eastern United States. Landscape and Urban Planning, 58, 255-268.

Bruekner, J. (2001). Urban Sprawl: Lessons from Urban Economics, Brookings-Wharton Papers on Urban Affairs, 1, 65-97.

Burton, E. (2001). The Compact City and Social Justice, A paper presented to the Housing Studies Association Spring Conference, Housing, Environment and Sustain ability, University of York.

Donnay, J. P., Barnsley, M. J., \& Longley, P. A. (2001). Remote Sensing and Urban Analysis. In DONNAY J.P., BARNSLEY M.J., LONGLEY P.A. (Eds.), Remote Sensing and Urban Analysis (pp. 3-18). Taylor \& Francis, London.

Dutta, V. (2012). Land Use Dynamics and Peri-urban Growth Characteristics: Reflections on Master Plan and Urban Suitability from a Sprawling North Indian City. Environment and Urbanization Asia, 3(2), 277-301.

Ewing, R., Pendall, R., \& Chen, D. (2002). Measuring Sprawl and its Impact, Smart Growth America, Washington D.C.

Galster, G., Hanson, R., Ratcliffe, M. R., Wolman, H., Coleman, S., \& Freihage, J. (2001). Wrestling Sprawl to the Ground: Defining and Measuring an Elusive Concept. Housing Policy Debate, 12(4), 681-717.

Gao, J., Liu, Y. S., \& Chen, Y. F. (2006). Land cover changes during agrarian restructuring in Northeast China. Appl. Geogr, 26, 312-322.

Ghanghermeh, A., Roshan, G., Orosa, A., Calvo-Rolle, J. L., \& Costa M. Á. (2013). New Climatic Indicators for Improving Urban Sprawl: A Case Study of Tehran City. Entropy, 15, 999-1013.

Hamin, E. M., \& Gurran, N. (2009). Urban form and climate change: Balancing adaptation and mitigation in the U.S. and Australia, Habitat International, 33, 238-245.

Hasse, J. E., \& Lathrop, R. G. (2003). Land Resource Impact Indicators of Urban Sprawl. Journal of Applied Geography, 23, 159-175.

Hayek, U., Jaeger, J. A. G., Schwick, C., Jarne, A., \& Schuler, M. (2011). Measuring and assessing urban sprawl: What are the remaining options for future settlement development in Switzerland for 2030? Applied Spatial Analysis and Policy, 4(4), 249-279.

Herold, M., Goldstein, N. C., \& Clarke, K. C. (2003). The spatiotemporal form of urban growth: Measurement, 
analysis and modeling. Remote Sensing of Environment, 86(3), 286-302.

Inostroza, L., Baur, R., \& Csaplovics, E. (2013). Urban Sprawl and Fragmentation in Latin America: A Dynamic Quantification and Characterization of Spatial Patterns. Journal of Environmental Management, 115, 87-97.

Jensen, J. R. (2005). Introductory Digital Image Processing: A Remote Sensing Perspective, Prentice- Hall, Upper Saddle River.

Jiang, F., Liu, S., Yuan, H., \& Zhang, Q. (2007). Measuring urban sprawl in Bejing with geo-spatial indices. Journal of Geographical Sciences, 17(4), 469-478. http://dx.doi.org/10.1007/s11442-007-0469-z

Johnson, M. P. (2001). Environmental impacts of urban sprawl: A survey of the literature and proposed research agenda. Environmental Planning A, 33, 717-735.

Kennedy, L. (2007). Regional industrial policies driving peri-urban dynamics in Hyderabad, India. Cities, 24(2), 95-109.

Kim, J., \& Ellis, C. (2009). Determining the Effects of Local Development Regulations on Landscape Structure: Comparison of the Woodlands and North Houston, TX. Landscape and Urban Planning, 92, 293-303.

Kumar, J. A. V., Pathan, S. K., \& Bhanderi, R. J. (2007). Spatio-temporal analysis for monitoring urban growth - a case study of Indore city. Journal of Indian Society of Remote Sensing, 35, 11-20.

Lata, K. M., Rao, C. H. S., Prasad, V. K., Badarianth, K. V. S, Rahgavasamy, V., \& Rao, C. H. S. (2001). Measuring urban sprawl: A case study of Hyderabad. GIS Development, 5, $26-29$.

Li, X., \& Yeh, A. G. (2004). Analysing Spatial Restructuring of Land Use Patterns in a Fast Growing Region Using Remote Sensing and GIS. Landscape Urban Plan, 69, 335-354.

Li, Y., Zhao, S., Zhao, K., Xie, P., \& Fang, J. (2006). Land-cover Changes in an Urban Lake Watershed in a Mega-city, Central China. Environmental Monitoring and Assessment, 115, 349-359.

Mohammady, S., Delavar, M. R., \& Pijanowski, B. C. (2013). Urban growth modeling using anfis algorithm: a case study for Sanandaj city, Iran, Int. Arch. Photogramm. Remote Sens. Spatial Inf. Sci., XL-1/W3, 493-498. Retrieved from http://www.int-arch-photogramm-remote-sens-spatial-inf-sci.net/ XL-1-W3/493/2013 /isprsarchives-XL-1-W3-493-2013.html

Muniz, T., \& Galindo, A. (2005). Urban form and the ecological footprint of commuting. The case of Barcelona, Ecol. Econs., 55, 499- 514.

Pijanowski, B. C., Pithadia, S., Shellito, B. A., \& Alexandridis, K. (2005). Calibrating a neural network-based urban change model for two metropolitan areas of Upper Midwest of the United States. Int. J. Geogr. Inf. Syst., 19(2), 197-215.

Pourahmad, A., Baghvand, A., Zangenehe, S., \& Givehchi, S. (2007). The Impact of Urban Sprawl up on Air Pollution. Int. J. Environ. Res., 1(3), 252-257.

Romano, B. (2004). Environmental Fragmentation Tendency. The Sprawl Index. ERSA - Porto, Portugal.

Roshan, G., Rousta, I., \& Ramesh, M. (2009). Studying the effects of urban sprawl of metropolis on tourism climate index oscillation: A case study of Tehran city. Journal of Geography and Regional Planning, 2(12), 310-321.

Rudel, T. K., \& Macdonald, K. (2005). Sprawl and forest cover: what is the relationship? Appl. Geogr., 25, $67-79$.

Sim, S., \& Mesev, V. (2011). Measuring urban sprawl and compactness: Case study Orlando, USA. International Cartographic Conference, Paris, France.

Sudhira, H. S., Ramachandra, T. V., \& Jagadish, K. S. (2004). Urban sprawl: metrics, dynamics and modeling using GIS. International Journal of Applied Earth Observations and Geoinformation, 5(1), 29-39.

Thomlinson, J. R., Bolstad, P. V., \& Cohen, W. B. (1999). Coordinating methodologies for scaling land cover classifications from site-specific to global: Steps toward validating global map products. Remote Sensing of Environment, 70, 16- 28.

Torrens, P. M., \& Alberti, M. (2000). Measuring sprawl. Working paper no. 27, Centre for Advanced Spatial Analysis, University College London.

Xie, J. Y., \& Cho, N. N. (2007). Spatial and temporal dynamics of urban sprawl along two urban-rural transects: a case study of Guangzhou, China. Landscape Urban Plan, 79(15), 96-109. 
Yeh, A. G. O., \& Li, X. (2001). Measurement and monitoring of urban sprawl in a rapidly growing region using entropy. Photogramm Eng Remote Sens, 67(1), 83-90.

Yeh, A. G., \& Li, X. (1999). Measurement of Urban Sprawl in a Rapid Growing Region Using Entropy. Towards Digital Earth - Proceedings of the International Symposium on Digital Earth, Science Press.

Zhang, T. (2000). Land market forces and government's role in sprawl. The case of China. Cities, 17(2), 123-135.

Zhang, X., Chen, J., Tan, M., \& Sun, Y. (2007). Assessing the impact of urban sprawl on soil resources of Nanjing city using satellite images and digital soil databases. Catena, 69, 16-30.

\section{Copyrights}

Copyright for this article is retained by the author(s), with first publication rights granted to the journal.

This is an open-access article distributed under the terms and conditions of the Creative Commons Attribution license (http://creativecommons.org/licenses/by/3.0/). 